\title{
Communicating Food Quality and Safety Standards in the Informal Market Outlets of Pastoral Camel Suusa and Nyirinyiri Products in Kenya
}

\author{
Madete S. K. Pauline ${ }^{1, ~ *, ~ B e b e ~ O . ~ B o c k l i n e ~}{ }^{2}$, Matofari W. Joseph ${ }^{1}$, Muliro S. Patrick ${ }^{1}$, \\ Mangeni B. Edwin ${ }^{3}$ \\ ${ }^{1}$ Department of Dairy and Food Science and Technology, Egerton University, Nakuru, Kenya \\ ${ }^{2}$ Department of Animal Sciences, Egerton University, Nakuru, Kenya \\ ${ }^{3}$ Livestock Sector, FAO Somalia, Nairobi, Kenya
}

Email address:

mdtpauline@yahoo.com (M. S. K. Pauline)

\section{To cite this article:}

Madete S. K. Pauline, Bebe O. Bockline, Matofari W. Joseph, Muliro S. Patrick, Mangeni B. Edwin. Communicating Food Quality and Safety Standards in the Informal Market Outlets of Pastoral Camel Suusa and Nyirinyiri Products in Kenya. Agriculture, Forestry and Fisheries. Vol. 4, No. 5, 2015, pp. 216-221. doi: 10.11648/j.aff.20150405.13

\begin{abstract}
The foods pastoral women process using indigenous knowledge have potential to enhance food security to households and health benefits to consumers but safety and quality concerns of consumers presents market barriers. This could be addressed through communicating food quality and safety standards. However, there are challenges in reaching the actors producing, processing and trading camel Suusa (spontaneously fermented milk) and Nyirinyiri (deep fried meat) because they are predominantly in the informal markets. This study identified communication strategies used to promote uptake of food quality and safety standards and level of awareness of actors along the value chains using data from survey, Focus Group Discussion (FGD) and Participatory appraisal. Results indicated low level of awareness among actors in the informal markets of Camel Suusa and Nyirinyiri. This can be attributed to underutilization of communication strategies to promote uptake of food quality and safety standards in the informal markets.
\end{abstract}

Keywords: Communication, Food Standards, Pastoral Women, Indigenous Technologies

\section{Introduction}

Food safety and quality standards are requirements in food systems for public health concerns at country of global level. Informal market outlets of camel Suusa and Nyirinyiri are some of the markets accessible only to the camel keeping communities. This is as a result of safety and quality concerns arising from growing application of agri-food value chain concept (Delia et al., 2010; Akweya et al., 2012) beyond the camel eating communities and niche markets. In rural households, most foods consumed are processed using indigenous technologies. This is true in the arid and semi-arid lands (ASAL) of Kenya where livestock and livestock products, mainly meat and milk are central in the diets and livelihoods.

In the arid and semi-arid lands (ASAL) of Kenya, pastoral households consume a substantial amount of food that is processed using indigenous technologies, especially meat and milk products. Of importance in the diets and livelihoods of pastoral households are camel meat (Nyirinyiri) and camel milk (Suusa) processed by women using indigenous knowledge food processing (IKFP). Processed camel meat (Nyirinyiri) and camel milk (Suusa) are also considered important for household food security and income from sales in the rural and urban market outlets. However, the pastoral women who play key role in indigenous knowledge food processing (IKFP) often have their families' food and income insecure because consumer acceptability of their IKFP products is low beyond traditional camel keeping communities and the quality is not ascertained.

Women's needs and knowledge should be taken into account when planning livestock projects and services. These will enhance their delivery of livestock services in pastoral areas. Identifying and supporting the roles, decision-making and capabilities of women as livestock owners, processors and users of livestock products are key aspects to promote women's economic and social empowerment and 
consequently a rural women's ability to break the cycle of poverty (IFAD, 2009, ILRI, 2008). Policy decisions should take women's roles and needs into account, and encourage a gendered perspective in livestock service delivery planning (Watson, 2010).

The existing policies on food safety discriminate against indigenous and informal food processors in favour of modern and formal processors. There is therefore the need to bridge the gap in uptake of food safety and quality standards in both informal and formal markets in order to break market barriers to niche markets for IKFP. This can be achieved through enhanced effective communication of the food safety and quality standards to actors in the value to increase awareness and uptake of the standards.

This study determined communication strategies that regulators use to promote awareness and uptake of food safety and quality standards and requirements in the informal market outlets of indigenous produced camel Suusa and Nyirinyiri.

\section{Methodology}

This study used survey, Focus Group Discussions (FGD) and participatory rapid appraisal approaches to sample actors along the camel Suusa and Nyirinyiri value chains in Isiolo, Marsabit and Nairobi (Eastleigh) where consumption of camel products is predominant in Kenya. Sampling targeted the value chain regulators, supporters and operators to identify communication strategies which they use in creating awareness on food safety and quality standards. Data collected was subjected to cross tabulation, Chi-square test statistics and post hoc Anova.

\section{Results and Discussion}

\subsection{The Age Bracket and Level of Education of Actors of Suusa and Nyirinyiri Value Chain}

Indigenous Knowledge Food Products are obtained using traditional knowledge unique to a given society or culture. From figure 1 below majority of the actors of Suusa and Nyirinyiri value chains are above 50 years of age. These individuals are highly skilled and knowledgeable in milk and meat production, Suusa and Nyirinyiri processing as well as the benefits of consuming such products. The least age bracket with 4 individuals is composed mainly of the transporters of fresh unprocessed milk and meat from the grazing sites and also transportation of Suusa and Nyirinyiri to town. Transportation of milk is mostly done by young men at different times of the day; early morning, midday and at night.

Figure 1 below illustrates the age bracket under which the actors of Suusa and Nyirinyiri value chain fell $(\mathrm{n}=70)$. Of the 70 , majority of the actors 28 fell in the age bracket of 51-60 years followed by 41-50 years with 21 actors. 3 of the actors were between the ages of 61-70 with at least four of them being above 70 years of age.

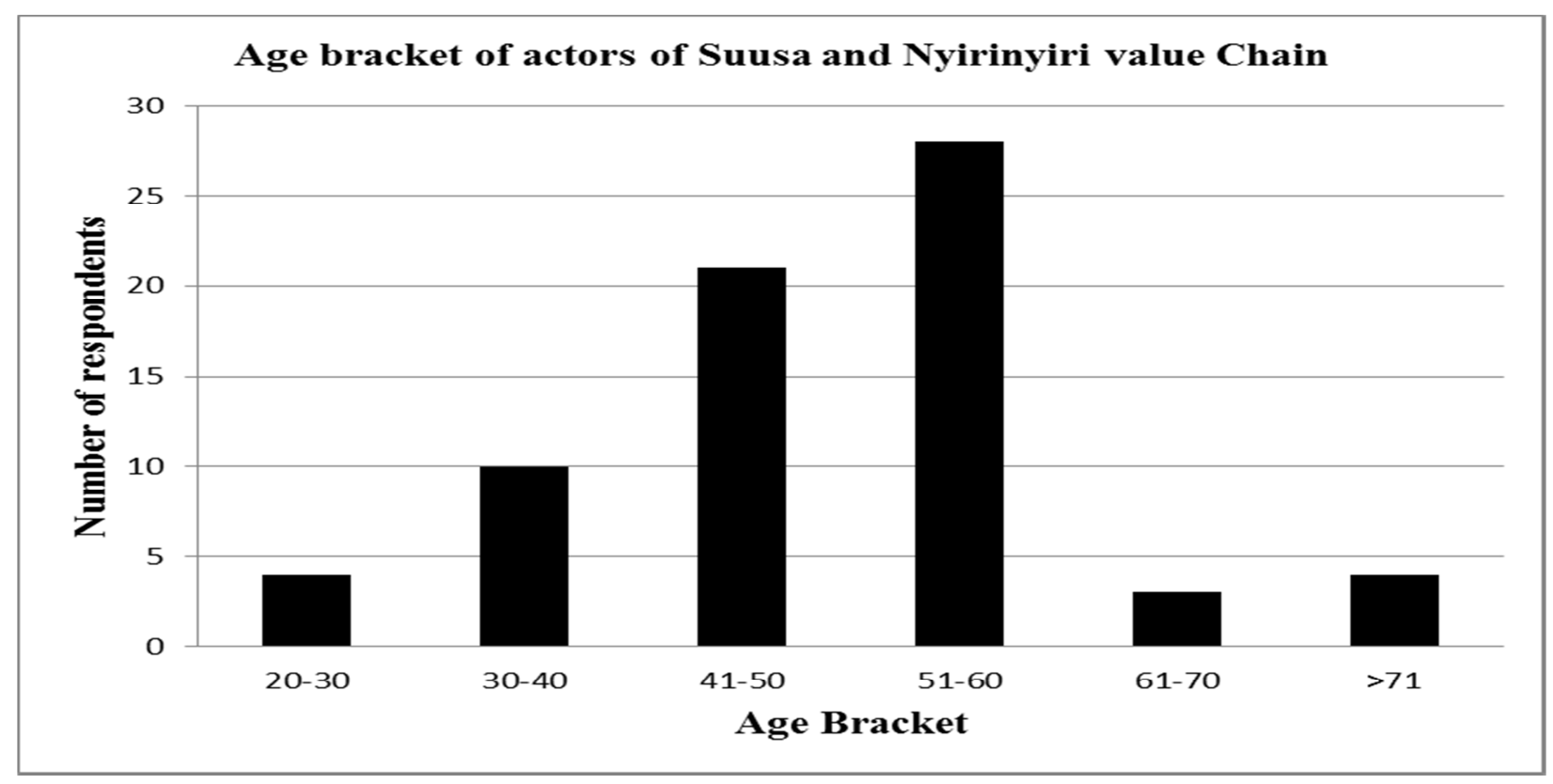

Figure 1. The age bracket of actors of Suusa and Nyirinyiri value chain.

The age of the value chain actors was complimented by the level of education and exposure of actors of Suusa and Nyirinyiri value chain to food quality and safety standards. Figure 2 below highlight the level of education of actors of Suusa and Nyirinyiri value chain. Of the actors of Suusa and Nyirinyiri value chain $(\mathrm{n}=70)$ only $37 \%$ had access to primary education, $7 \%$ secondary education, $1 \%$ tertiary education, with majority of them at $52 \%$ having no access to education. $3 \%$ of the actors mentioned that they had a different form of education. Training done by Vital Camel Milk and VSF were termed as other forms of education. Through these trainings some food quality and safety aspects were passed onto actors of Suusa and Nyirinyiri value Chains. 


\section{Level of Education of actors of Suusa and Nyirinyiri Value Chain}

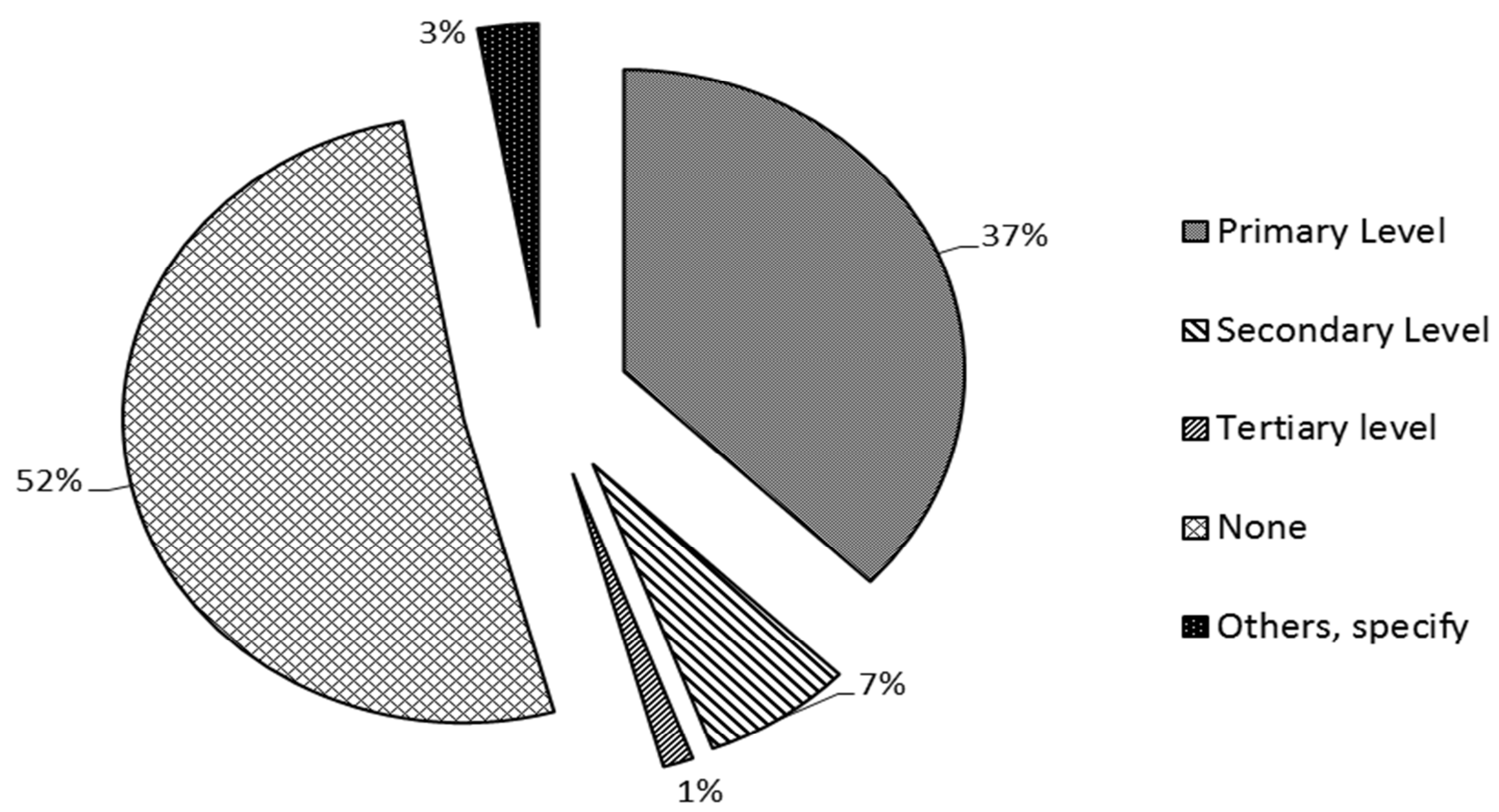

Figure 2. The Level of Education of Actors of Suusa and Nyirinyiri value chain.

Socio-economic characteristics of a farmer such as level of poverty, farming experience, age and education influence the adoption food quality and safety standards (Hudson and Hite, 2003). Looking at figure 2 above low levels of education or no education at all is hampering the understanding and uptake of food quality and safety standards in the informal market outlets of indigenous knowledge food products. Hence, for Camel Suusa and Nyirinyiri processors to adopt food safety and quality standards depends on factors such as access to institutional services, in-put supply markets and effective communication strategies (Khan 2005).

Age and level of education is related to production experience and also directly influences information access for formal and inform market outlets camel processors. In general, older farmers are less willing to try out new innovations or take risks compared to younger farmers, older farmers are less likely to engage in simultaneous receiving and providing of information, perhaps due to their low ability to communicate (Katungi, 2006).

Individuals can perceive the risk from the same hazard very differently. Some of the public may disagree with risk assessors and managers regarding important hazard characteristics, the relative magnitude or severity of the risks associated with those hazards, the priority of risks, and other issues. Other segments of the public also may not pay attention to risk information if the message does not address their actual concerns, but instead addresses only technical risk assessments provided by the experts (FAO/WHO, 2002).

\subsection{Level of Awareness About Food Safety and Quality Standards}

Figure 3 illustrates level of awareness on food safety and quality standards among the actors in Suusa and Nyirinyiri value chains. Of all the sampled actors $(n=70)$, the level of awareness was low (23\%) and peaked at 30\% among processors and retailers (market traders) with transporters being the least aware (13\%).

For those actors aware of the food safety and quality standards, specific aspects known to them were further examined and results are illustrated in Figure 4. Actors' awareness was highest on packaging conditions (25\%) and on processing hygiene and purchasing conditions (19\%) and lowest on environmental and transportation hygiene $(6 \%)$.

In Kenya, the standard requirement bar transportation of milk with other goods and use non-food grade containers (Lusato, 2006). However, these requirements are often violated as products are traditionally transported in plastic jericans with other goods and animals to the destined markets in vans or buses from Isiolo and Marsabit to Nairobi urban markets. 


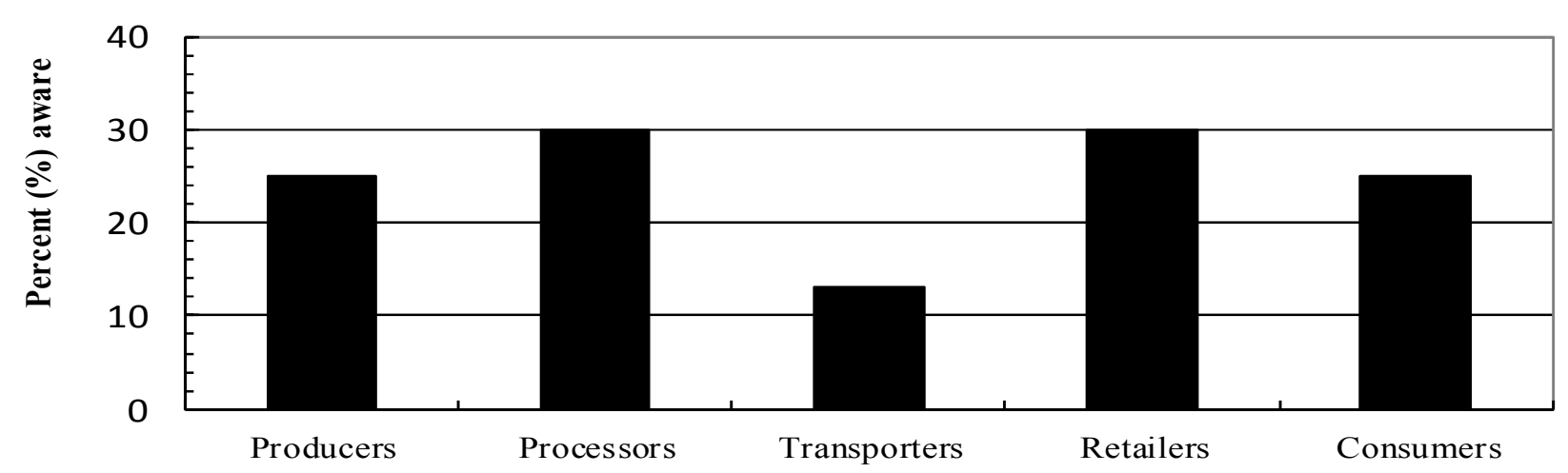

Value chain Actors

Figure 3. Awareness about food safety and quality standards among actors in value chains of camel Suusa and Nyirinyiri sampled in the e informal markets outlets.

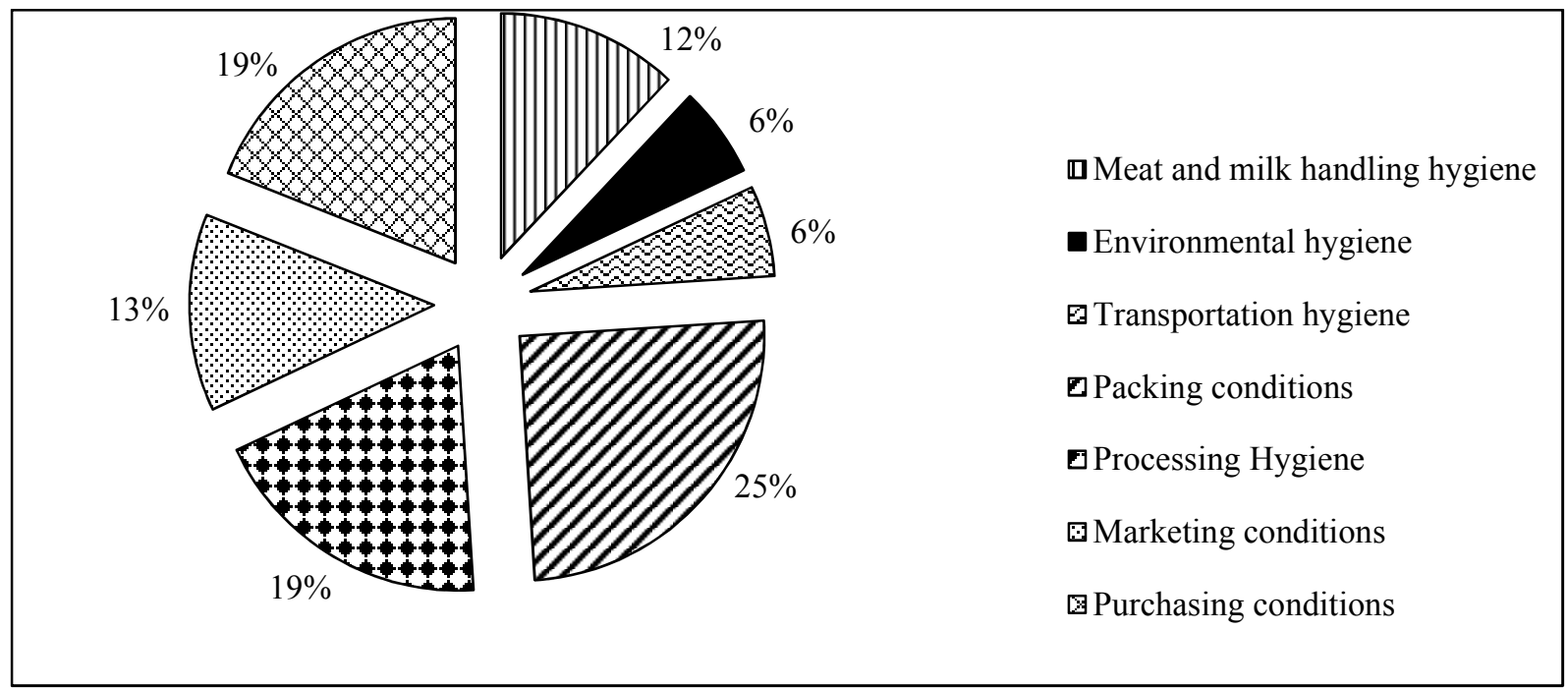

Figure 4. Specific aspects know to the actors of Suusa and Nyirinyiri value chain.

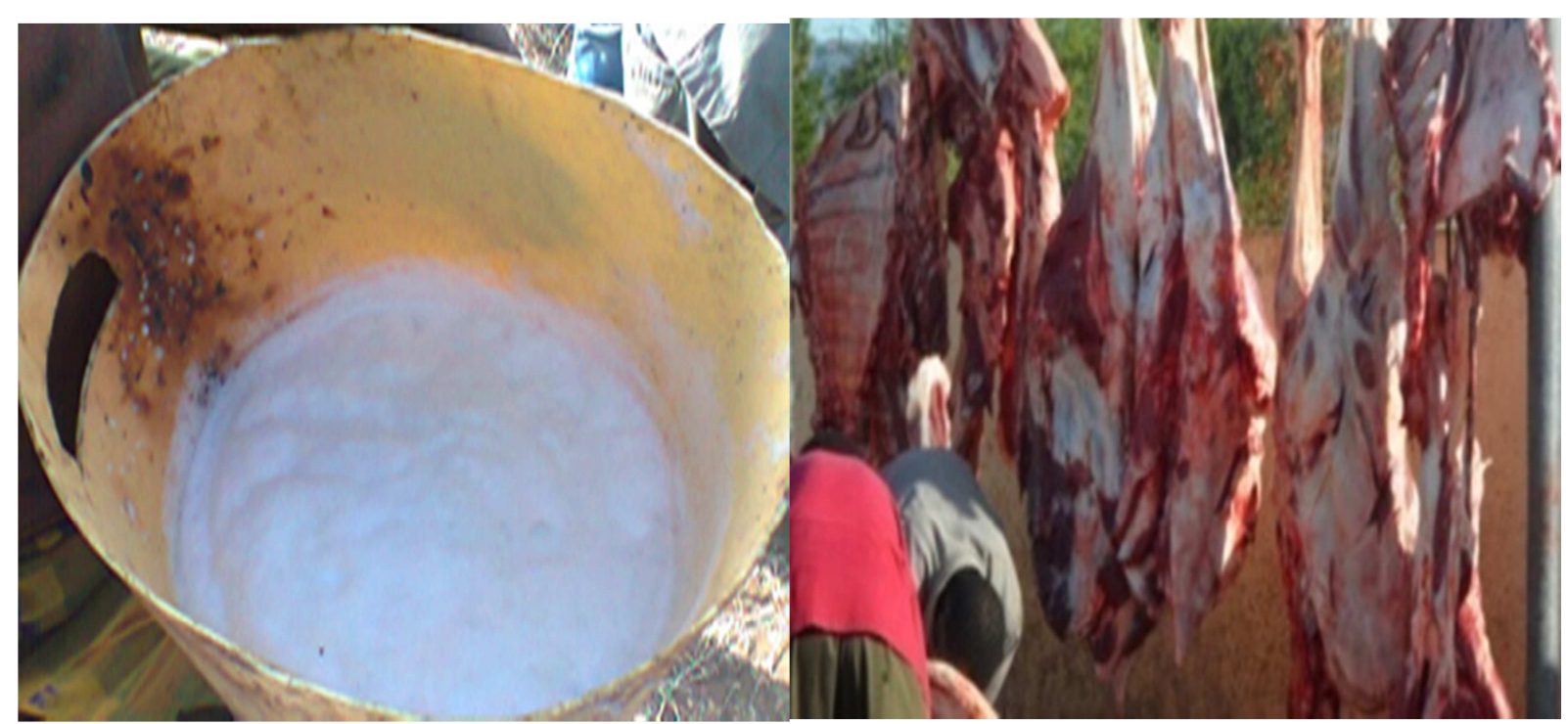

Plate 1. Handling practices of the milk and meat products in pastoral areas. 


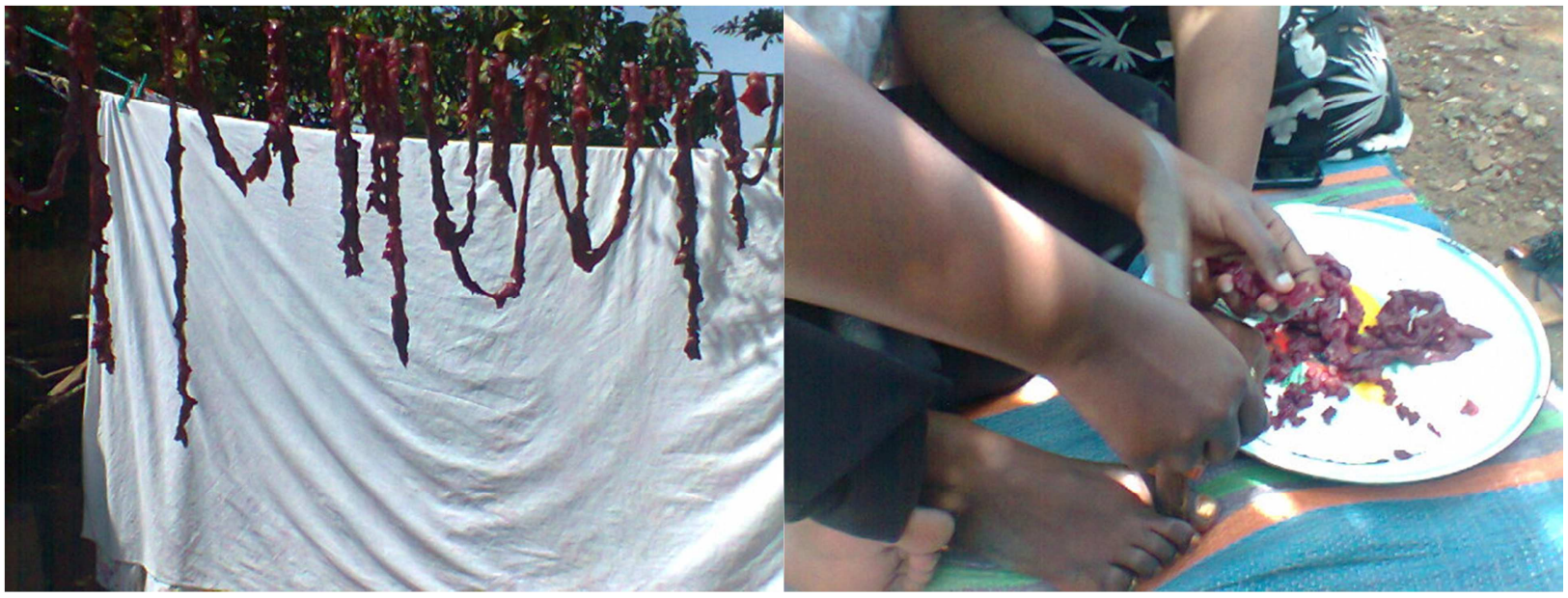

Plate 2. Highlight the handling hygiene of fresh camel meat just before processing using indigenous knowledge.

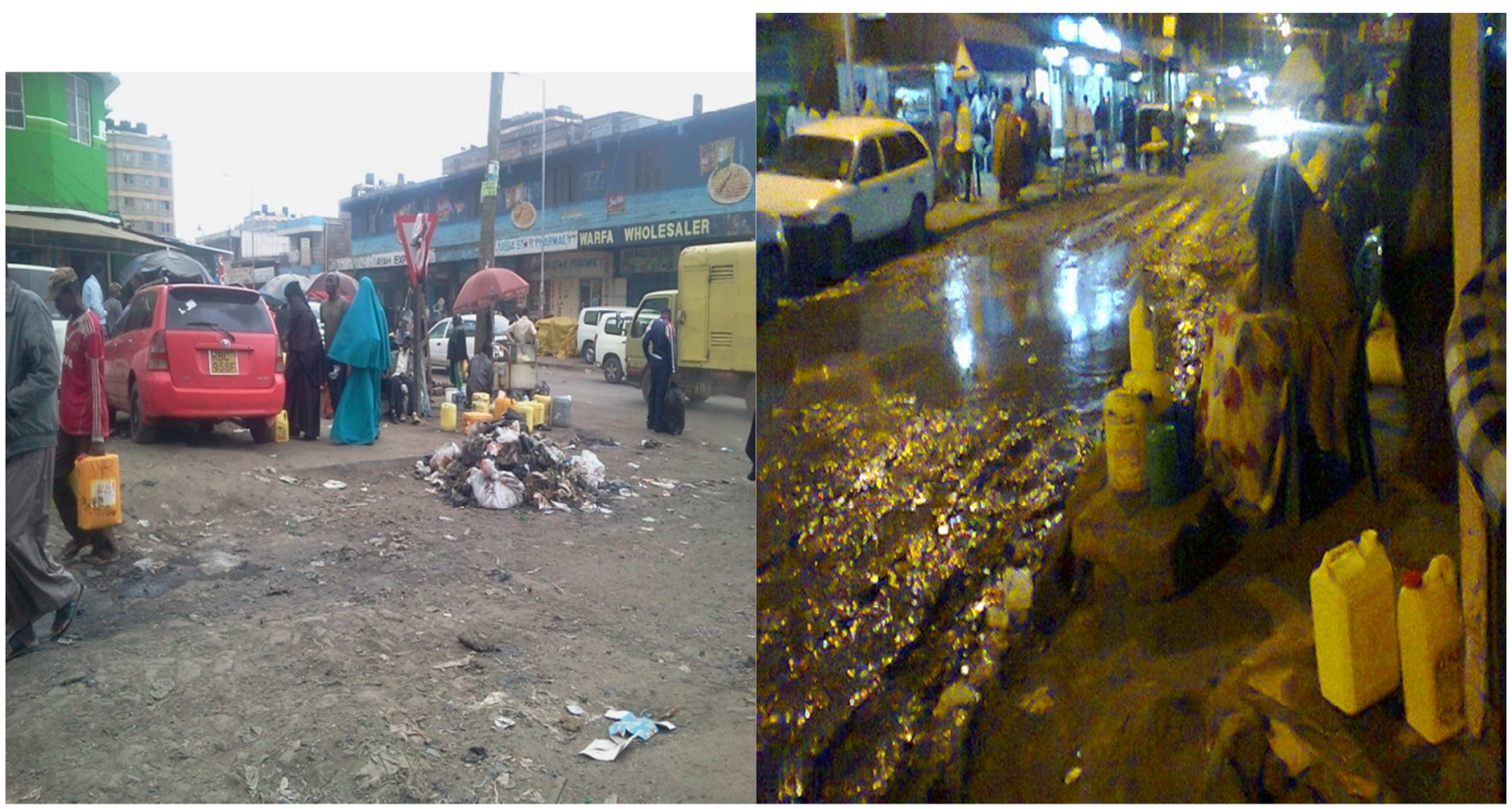

Plate 3. Captures Eastleigh market in Nairobi for Suusa and Nyirinyiri.

Plate 1 illustrates the poor milk and meat handling hygiene practices at production among the sample actors using unclean plastic containers which is attributable to lack of water.

Herders do milk camels on transit; use discolored dirty plastic containers without adequate washing of hands, udder and containers before milking. The milking environment is generally unhygienic with a lot of animal waste and polythene wastes. Although milk was commonly boiled before consumption, handling practices and wide spread lack of refrigeration across the value chain potentially pose increased health risks. In meat handling the slaughter houses had partial covered roofing, insufficient and unclean water supply, unwashed and cleaned slabs and workers with dirty protective clothing. These observations reflect unhygienic handling of carcasses related to the environment (Plate 1-3).

\subsection{Communication Strategies for Creating Awareness on Food Safety and Quality Standards}

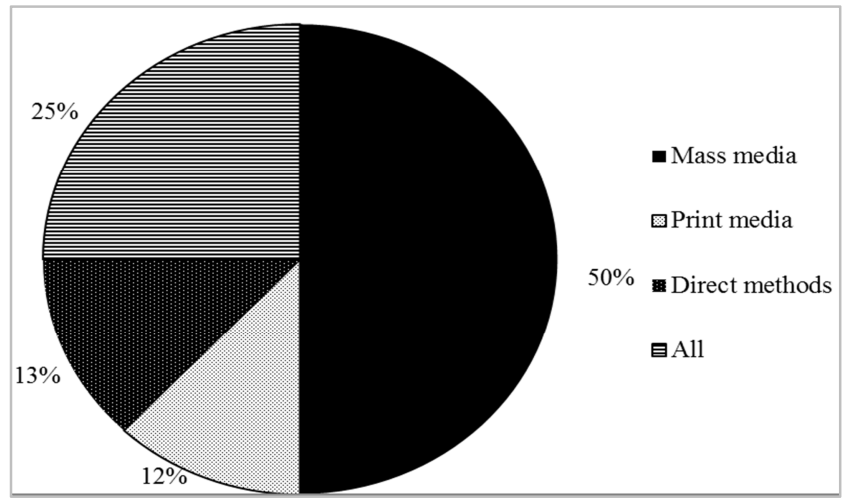

Figure 5. Communication strategies used by regulators and information service providers in the formal market outlet 
Figure5 shows that of the various communication strategies used by regulators and information service providers in promoting uptake of food quality and safety standards in the informal markets, mass media dominated $(43 \%)$ complemented with print media and direct contacts $(29 \%)$. Maina (2006) noted that using radio has achieved impressive results in the delivery of useful information to poor people. FM stations have become handy tools in small scale agriculture in rural areas and in facilitating dissemination of market information but have been less exploited in communicating food quality and safety standards in the informal market outlets of Suusa and Nyirinyiri to raise awareness and upscale uptake.

Survey results in figure 5 could not identify any communication strategy specifically targeted to promoting awareness and uptake of food safety and quality standards in the informal market outlets of camel Suusa and Nyirinyiri. The communication strategies mentioned in Figure 5 are best suited to communicating formal food quality and safety standards as part of risk communication in formal market outlets. Moreover, the standards being communicated are generated are in line with international standards mainly because they deal with large industries and firms. Indigenous knowledge has not been in cooperated into their knowledge source hence it has been given less attention. This therefore calls for an in-depth knowledge on how to integrate indigenous and scientific knowledge with an aim of developing safety and quality standards suited for the informal market outlets of camel Suusa and Nyirinyiri.

\section{Conclusion and Recommendation}

Adoption of food quality and safety standards remains elusive in the informal market outlets. Communication strategies used by regulators do not adequately cater for the informational needs in the informal market outlets of camel Suusa and Nyirinyiri. This study aimed at identifying communication strategies used in communicating food quality and safety standards in line with the awareness on food quality and safety standards in the informal market outlets. There is a general low level of awareness about food safety and quality among actors in the value chains of camel Suusa and Nyirinyiri in the informal market outlets. This can be attributed to underutilization of formal communication strategies to promote uptake of food quality and safety standards in the informal markets. There is the need therefore for reviewing formal communication strategies with potential to reaching more actors in the informal markets of Indigenous Knowledge Food Products (IKFP). With increased outreach there is a perceived benefit for both pastoral women processors and consumers informal market outlets.

\section{Acknowledgements}

This work was supported by a grant from RUFORUM which the authors are grateful to. The authors would also like to thank Egerton University and pastoral women processors in ASAL areas of Isiolo and Marsabit Kenya and consumers of indigenous camel products of Suusa and Nyirinyiri.

\section{References}

[1] Akweya B. A., Gitao C. G., Okoth M. W. (2012). The acceptability of camel milk and milk products from North Eastern province in some urban areas Kenya. African Journal of Food Science Vol 6(19) pg 465-473.

[2] Delia G, Makita K., Kang'ethe E. K., Bonfoh B. (2010). Safe Food, Fair Food: Participatory Risk Analysis for improving the safety of informally produced and marketed food in sub Saharan Africa http://www.ilri.org/ilrinews/index.php/archives/tag/delia-grace

[3] FAO/WHO. (2002). Post- harvest technology and food quality. Part 6.Science and technology for sustainable development FAO/WHO. Joint FAO/WHO Food Standards Programme Report of the Sixteenth Session of FAO/WHO Coordinating Committee for Africa, Codex Alimentarius Commission FAO. Rome. 25 - 28 January 2005.

[4] Hudson, D. and Hite, D. (2003). Willingness to Pay for Water Quality Improvements: The Case of Precision Application Technology. Journal of Agricultural Resource Economics, 27: 433-449.

[5] IFAD. (2009). Rota, A. and Sperandini, S. "Value chains, linking producers to the markets", in Livestock Thematic Papers: Tools for project design. Rome: International Fund for Agricultural Development (IFAD).

[6] International Livestock Research Institute (ILRI). (2008). Policy change in dairy marketing in Kenya: Economic impact and pathway to influence research. www.ilri.org/ilribriefs/index.php/pdf. Retrieved on 16/03/2013.

[7] Katungi, E. (2006). Gender, Social Capital and Information Exchange in Rural Uganda IFPRI and Melinda Smale, IFPRI (International Food Policy Research Institute) CAPRi Working Paper (59), University of Pretoria. Uganda. Retrieved on March 01, 2012 from: $<$ http://www.capri.cgiar.org/pdf/capriwp59.pdf $>$

[8] Khan, S. A. (2005). Introduction to Extension Education in Memon, R. A. and E. Bashir (eds.). Extension Methods (3rd ed.). National Book Found, Islamabad, Pakistan

[9] Lusato K. R. (2006). Hygienic milk handling, processing and marketing: reference guide for training and certification of small-scale milk traders in Eastern Africa. ILRI. Nairobi, Kenya.http://www.ilri.org/Link/Publications/Theme3/Trainer GuideVol-1_Cmprss.pdf.

[10] Maina w. Lucy. (2006). African media initiative Kenya. Research findings and conclusion 2006.BBC world service. http://africanmediainitiative.org/content/2013/07/22/AMDI-B BC-summary-report.pdf. 